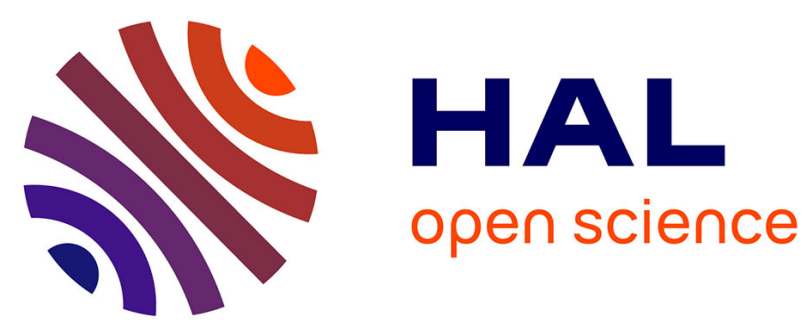

\title{
New method for individual electrical characterization of stacked SOI nanowire MOSFETs
}

\author{
Bruna Cardoso Paz, Mikaël Cassé, Sylvain Barraud, Gilles Reimbold, Maud
} Vinet, Olivier Faynot, Marcelo Antonio Pavanello

\section{To cite this version:}

Bruna Cardoso Paz, Mikaël Cassé, Sylvain Barraud, Gilles Reimbold, Maud Vinet, et al.. New method for individual electrical characterization of stacked SOI nanowire MOSFETs. 2017 IEEE SOI-3D-Subthreshold Microelectronics Technology Unified Conference (S3S), Oct 2017, Burlingame, United States. 10.1109/S3S.2017.8309237 . cea-01974212

\section{HAL Id: cea-01974212 https://hal-cea.archives-ouvertes.fr/cea-01974212}

Submitted on 8 Jan 2019

HAL is a multi-disciplinary open access archive for the deposit and dissemination of scientific research documents, whether they are published or not. The documents may come from teaching and research institutions in France or abroad, or from public or private research centers.
L'archive ouverte pluridisciplinaire HAL, est destinée au dépôt et à la diffusion de documents scientifiques de niveau recherche, publiés ou non, émanant des établissements d'enseignement et de recherche français ou étrangers, des laboratoires publics ou privés. 


\title{
New method for individual electrical characterization of stacked SOI nanowire MOSFETs
}

\author{
Bruna Cardoso Paz ${ }^{\mathrm{a}}$, Mikaël Cassé ${ }^{\mathrm{b}}$, Sylvain Barraud ${ }^{\mathrm{b}}$, Gilles Reimbold ${ }^{\mathrm{b}}$, Maud Vinet ${ }^{\mathrm{b}}$, Olivier Faynot ${ }^{\mathrm{b}}$ and Marcelo \\ Antonio Pavanello ${ }^{\mathrm{a}}$ \\ ${ }^{a}$ Centro Universitário FEI, Av. Humberto de A. C. Branco, 3972, 09850-901 - São Bernardo do Campo - Brazil \\ ${ }^{\mathrm{b}}$ CEA, LETI, MINATEC Campus, 17 rue des martyrs 38054 Grenoble - France \\ bcpaz@fei.edu.br
}

\begin{abstract}
A new systematic procedure to separate the electrical characteristics of advanced stacked nanowires (NWs) with emphasis on mobility extraction is presented. The proposed method is based on I-V measurements varying the back gate bias $\left(V_{B}\right)$ and consists of three basic main steps, accounting for $V_{B}$ influence on transport parameters. Lower mobility was obtained for the top GAA NW in comparison to bottom $\Omega-N W$. Temperature dependence of carrier mobility is also studied through the proposed method up to $150^{\circ} \mathrm{C}$.
\end{abstract}

Keywords—stacked nanowires; mobility; back gate bias; SOI

\section{INTRODUCTION}

Aggressively scaled multiple-gate transistors, such as nanowire MOSFETs, have demonstrated excellent performance and strong immunity against short channel effects, due to improved electrostatics [1]. Thanks to advances in fabrication process steps, such structures can be vertically stacked in order to fulfill higher drive current requests [2]-[4]. Reducing the intrinsic parasitic capacitances and boosting carriers' mobility are considered two of the main challenges to implement stacked NWs for future technological nodes. Aiming to step up into the solution of these problems, vertically stacked p-NWs combining both inner spacers and SiGe S/D have been recently fabricated [3]. Overall performance and transport of these stacked NWs have been investigated in [5], but still no individual electrical characterization of each NW level is available, which could be valuable for technology optimization. A methodology to separate the channels conduction was firstly proposed and applied to Multi-Gate devices using the effect of the applied back bias $V_{B}$ [6]. However this method does not take into account the low field effect mobility $\left(\mu_{0}\right)$ dependence on $V_{B}$ [7]. In this work, we improved the methodology in [6] by including explicit expressions for $\mu_{0}$ and mobility degradation coefficients $\left(\theta_{1}\right.$ and $\left.\theta_{2}\right)$ dependence on $V_{B}$, based on measurements and modelling. The proposed method is applied to advanced narrow stacked NWs from room to high temperature for a better understanding of their electrical characteristics.

\section{DEVICES AND MEASUREMENTS}

Two levels vertically stacked SOI NWs MOSFETs have been fabricated at CEA-LETI with a replacement metal gate process, integrating inner spacers and $\mathrm{Si}_{0.7} \mathrm{Ge}_{0.3}$ :B raised $\mathrm{S} / \mathrm{D}$ (Fig.1). Further fabrication details can be found in [3]. The bottom NW presents $\Omega$-shaped gate and depends electrostatically on $V_{B}$, while the top wire is GAA (Gate-AllAround) and independent of $\mathrm{V}_{\mathrm{B}}$. The proposed methodology uses this $V_{B}$ dependence to dissociate $\Omega$ - and GAA-NWs electrical properties.

Fig. 2 presents the drain current $\left(\mathrm{I}_{\mathrm{DS}}\right)$ and its second derivative $\left(\delta \mathrm{g}_{\mathrm{m}} / \delta \mathrm{V}_{\mathrm{GS}}\right)$ as a function of the front gate voltage $\left(\mathrm{V}_{\mathrm{GS}}\right)$ for narrow $\mathrm{NW}$ varying $\mathrm{V}_{\mathrm{B}}$. From the logarithmic $\mathrm{I}-\mathrm{V}$
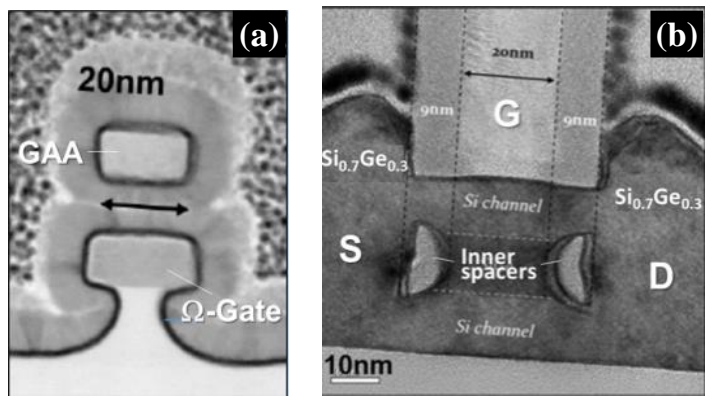

Fig. 1. TEM images of vertically stacked SOI NW cross section (a) and longitudinal section (b). Both top and bottom Si channels are $10 \mathrm{~nm}$ thick. BOX thickness is $145 \mathrm{~nm}$. Gate stack is composed by $\mathrm{HfO}_{2} / \mathrm{TiN} / \mathrm{W}$ (EOT $\sim 1.2 \mathrm{~nm}$ ). $\mathrm{W}_{\mathrm{FIN}}$ indicates the top width of the NWs.

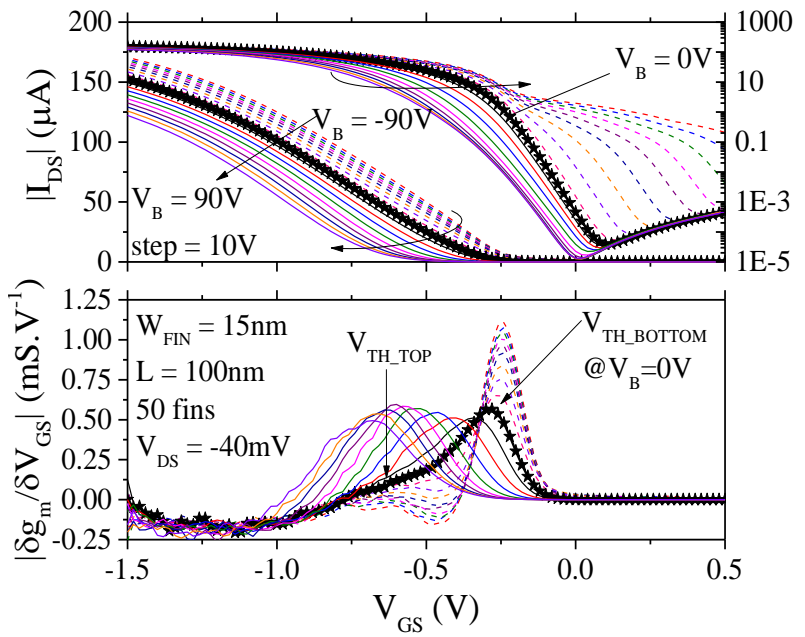

Fig. 2. $\left|\mathrm{I}_{\mathrm{DS}}\right|$ and $\left|\delta \mathrm{g}_{\mathrm{m}} / \delta \mathrm{V}_{\mathrm{GS}}\right|$ vs. $\mathrm{V}_{\mathrm{GS}}$ for stacked $\mathrm{NW}, \mathrm{W}_{\mathrm{FIN}}=15 \mathrm{~nm}, \mathrm{~L}=$ $100 \mathrm{~nm}, \mathrm{~V}_{\mathrm{DS}}=-40 \mathrm{mV}$ and $\mathrm{V}_{\mathrm{B}}$ from -90 to $90 \mathrm{~V}$ 
curves, it is observed that back conduction (BC) appears for negative $V_{B}$. The derivative of the transconductance $\left(g_{m}\right)$ shows two distinguished peaks: one constant and insensitive to $\mathrm{V}_{\mathrm{B}}$, related to the threshold voltage $\left(\mathrm{V}_{\mathrm{TH}}\right)$ of the top $\mathrm{NW}$ ( $\mathrm{V}_{\mathrm{TH}_{-} \text {тоP }}$ ), and another one sensitive to $\mathrm{V}_{\mathrm{B}}$, corresponding to bottom $\Omega-\mathrm{NW}$ threshold voltage ( $\left.\mathrm{V}_{\text {TH_воттом}}\right)$. No peak is observed due to $\mathrm{BC}$ because its contribution is almost negligible, as expected in narrow $\Omega$-NWs. Fig. 3 shows both $\mathrm{V}_{\mathrm{TH}}$ extracted from $\delta \mathrm{g}_{\mathrm{m}} / \delta \mathrm{V}_{\mathrm{GS}}$ peaks and the subthreshold slope (S). For $\mathrm{V}_{\mathrm{B}}<-10 \mathrm{~V}$ there is $\mathrm{BC}$, so $\mathrm{V}_{\mathrm{TH} \_ \text {Bоттом }}$ is constant and $\mathrm{S}$ degrades with $\mathrm{V}_{\mathrm{B}}$ reduction. For $\mathrm{V}_{\mathrm{B}}>-10 \mathrm{~V} \mathrm{~V}_{\text {тн_воттом }}$ decreases with $V_{B}$ increase. Due to thin silicon layer, the bottom NW never reaches accumulation [8]. Applying high positive $\mathrm{V}_{\mathrm{B}}(>50 \mathrm{~V}), \mathrm{V}_{\text {TH_Bоттом }}<\mathrm{V}_{\mathrm{TH} \_ \text {TOP }}$ and $\mathrm{V}_{\mathrm{TH}}$ and $\mathrm{S}$ are determined by the GAA-NW.

\section{ANAYSIS AND DISCUSSION}

By applying the Y-function method [9] to the measured $\mathrm{I}_{\mathrm{DS}}$, it is possible to extract the overall parameters related to the sum of $\Omega$ - and GAA-NW contributions. The proposed method uses 3 steps.

Step 1.- As the GAA-NW is $V_{B}$ independent, if the region of main interest where the $\mathrm{Y}$-function is applied is carefully chosen (Fig.4-a), the extracted $\theta_{1}\left(V_{B}\right), \theta_{2}\left(V_{B}\right)$ and $\mu_{0}\left(V_{B}\right)$ can be exclusively attributed to the bottom $\Omega-N W$. A linear behavior is verified between the transport parameters and $V_{B}$. The same linear behavior has been observed for reference wafers with non-stacked TriGate (TG) NWs with similar dimensions, as indicated in Fig.6. Linear fittings of $\theta_{1}\left(V_{B}\right)$, $\theta_{2}\left(V_{B}\right)$ and $\mu_{0}\left(V_{B}\right)$ lead to the extraction of corresponding slope and intercept, i.e. $\theta_{1, \Omega \mathrm{G}}=\mathrm{A}_{\theta 1}+\mathrm{a}_{\theta 1} \times \mathrm{V}_{\mathrm{B}}, \theta_{2, \Omega \mathrm{G}}=\mathrm{B}_{\theta_{2}}+\mathrm{b}_{\theta 2} \times \mathrm{V}_{\mathrm{B}}$ and $\mu_{0, \Omega G}=C_{\mu 0}+c_{\mu 0} \times V_{B}$. Fig. 4-a shows measurements and fitted lines of $g_{m}$ as a function of $V_{G s}$. The peak variation with $\mathrm{V}_{\mathrm{B}}$ clearly indicates its influence on the mobility parameters of the $\Omega-N W$, which is the reason why this region was selected for applying the $\mathrm{Y}$-function in this step. Negative $\mathrm{V}_{\mathrm{B}}$ values are chosen because $\mathrm{V}_{\text {TH_воттом }}$ is constant and $\Omega-\mathrm{NW}$ current shift does not affect the extraction.

Step 2.- For $\mathrm{V}_{\mathrm{B}} \geq 0$, there is no $\mathrm{BC}$ and $\mathrm{I}_{\mathrm{DS}}\left(\mathrm{V}_{\mathrm{B}} \geq 0\right)=$ $\mathrm{I}_{\mathrm{DS}, \Omega \mathrm{G}}\left(\mathrm{V}_{\mathrm{B}}\right)+\mathrm{I}_{\mathrm{DS}, \mathrm{GAA}}(1)$, where $\Omega$ - and GAA-NWs drain

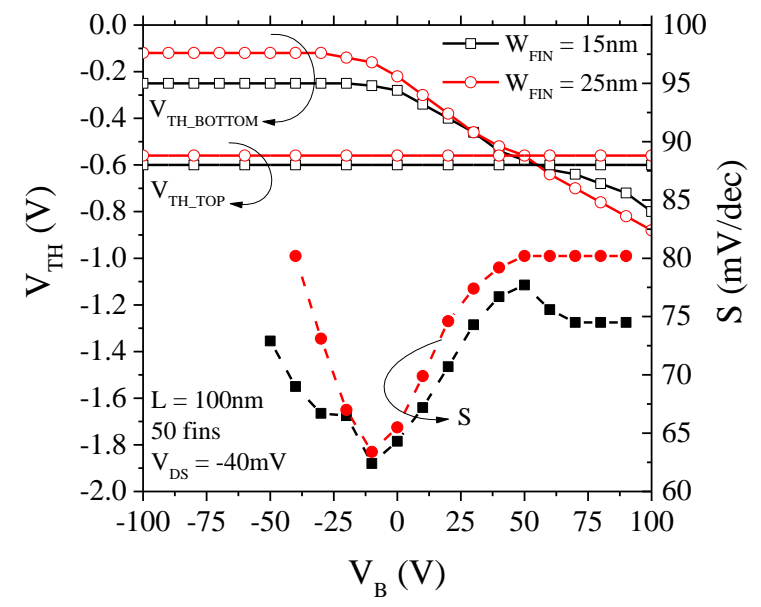

Fig. 3. $\mathrm{V}_{\mathrm{TH}}$ and $\mathrm{S}$ vs. $\mathrm{V}_{\mathrm{B}}$ for NWs with $\mathrm{W}_{\mathrm{FIN}}=15$ and $25 \mathrm{~nm}, \mathrm{~L}=100 \mathrm{~nm}$ and $V_{D S}=-40 m V$. currents (at low $\mathrm{V}_{\mathrm{DS}}$ ) are given by:

$$
\begin{aligned}
& \mathrm{I}_{\mathrm{DS}, \Omega \mathrm{G}}\left(\mathrm{V}_{\mathrm{B}}\right)= \\
& \frac{\mathrm{W}_{\mathrm{eff}, \Omega \mathrm{G}} \times \mathrm{C}_{\mathrm{OX}}}{\mathrm{L}} \frac{\mu_{0, \Omega \mathrm{G}}\left(\mathrm{V}_{\mathrm{B}}\right) \times \mathrm{V}_{\mathrm{GT}, \Omega \mathrm{G}}\left(\mathrm{V}_{\mathrm{B}}\right) \times \mathrm{V}_{\mathrm{DS}}}{1+\theta_{1, \Omega \mathrm{G}}\left(\mathrm{V}_{\mathrm{B}}\right) \times \mathrm{V}_{\mathrm{GT}, \Omega \mathrm{G}}\left(\mathrm{V}_{\mathrm{B}}\right)+\theta_{2, \Omega \mathrm{G}}\left(\mathrm{V}_{\mathrm{B}}\right) \times \mathrm{V}_{\mathrm{GT}, \Omega \mathrm{G}}{ }^{2}\left(\mathrm{~V}_{\mathrm{B}}\right)} \\
& \mathrm{I}_{\mathrm{DS}, \mathrm{GAA}}=\frac{\mathrm{W}_{\mathrm{eff}, \mathrm{GAA}} \times \mathrm{C}_{\mathrm{OX}}}{\mathrm{L}} \frac{\mu_{0, \mathrm{GAA}} \times \mathrm{V}_{\mathrm{GT}, \mathrm{GAA}} \times \mathrm{V}_{\mathrm{DS}}}{1+\theta_{1, \mathrm{GAA}} \times \mathrm{V}_{\mathrm{GT}, \mathrm{GAA}}+\theta_{2, \mathrm{GAA}} \times \mathrm{V}_{\mathrm{GT}, \mathrm{GAA}}{ }^{2}}
\end{aligned}
$$

$\mathrm{V}_{\mathrm{GT}}$ is the gate voltage overdrive $\left(\mathrm{V}_{\mathrm{GT}}=\mathrm{V}_{\mathrm{GS}}-\mathrm{V}_{\mathrm{TH}}\right)$. Considering that mismatches of $\mathrm{W}_{\mathrm{FIN}}$ and $\mathrm{t}_{\mathrm{Si}}$ between $\Omega$ - and GAA-NWs are negligible, as suggested in Fig.1, the effective channel widths are $\mathrm{W}_{\text {eff, }, \mathrm{G}}=\left(2 \mathrm{t}_{\mathrm{Si}}+\mathrm{W}_{\mathrm{FIN}}\right)$ and $\mathrm{W}_{\text {eff,GAA }}=\left(2 \mathrm{t}_{\mathrm{Si}}+\right.$ $\left.2 \mathrm{~W}_{\mathrm{FIN}}\right)$. The linear behavior with $\mathrm{V}_{\mathrm{B}}$ is attributed to mobility parameters of the $\Omega-\mathrm{NW}$. The subtraction of total drain currents at different $V_{B} \geq 0$ leads to an expression that only depends on $\mathrm{I}_{\mathrm{DS}, \Omega \mathrm{G}}$ :

$$
\begin{aligned}
\Delta \mathrm{I}_{\mathrm{DS}}\left(\mathrm{V}_{\mathrm{B}}\right)=\mathrm{I}_{\mathrm{DS}}\left(\mathrm{V}_{\mathrm{B} 1} \geq 0\right)-\mathrm{I}_{\mathrm{DS}}\left(\mathrm{V}_{\mathrm{B} 2}>\mathrm{V}_{\mathrm{B} 1}\right)= \\
\mathrm{I}_{\mathrm{DS}, \Omega \mathrm{G}}\left(\mathrm{V}_{\mathrm{B} 1}\right)-\mathrm{I}_{\mathrm{DS}, \Omega \mathrm{G}}\left(\mathrm{V}_{\mathrm{B} 2}\right)
\end{aligned}
$$

As indicated in Fig.4-b, the fitting procedures of (4) allow to determine $\mathrm{A}_{\theta 1}, \mathrm{~B}_{\theta 2}$ and $\mathrm{C}_{\mu 0}$.
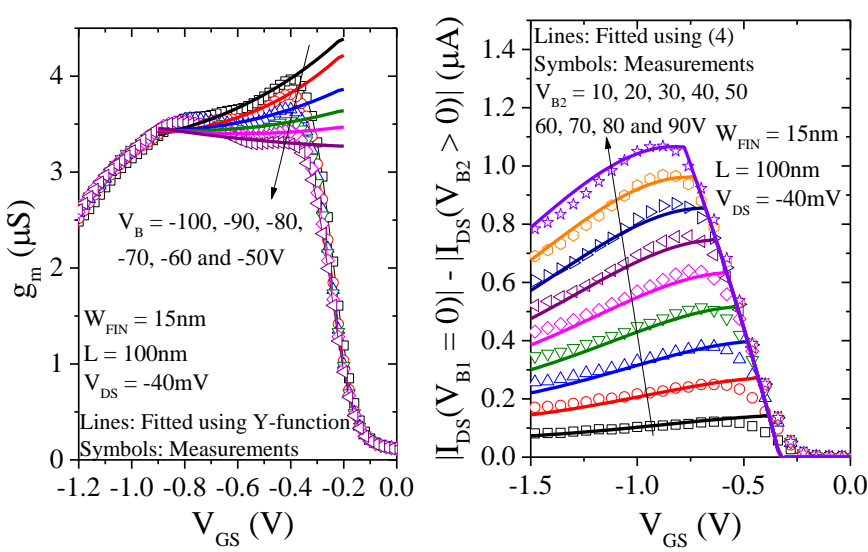

Fig. 4. (a) Step 1. Measurements and model results of $g_{m} v s$. $V_{G S}$ for $N W$ with $\mathrm{W}_{\mathrm{FIN}}=15 \mathrm{~nm}, \mathrm{~L}=100 \mathrm{~nm}$ and $\mathrm{V}_{\mathrm{DS}}=-40 \mathrm{mV}$. (b) Step 2. Measurements and model results of $\Delta \mathrm{I}_{\mathrm{DS}}$ vs. $\mathrm{V}_{\mathrm{GS}}$ for $\mathrm{NW}$ with $\mathrm{W}_{\mathrm{FIN}}=15 \mathrm{~nm}, \mathrm{~L}=100 \mathrm{~nm}$ and $\mathrm{V}_{\mathrm{DS}}=-40 \mathrm{mV}$.
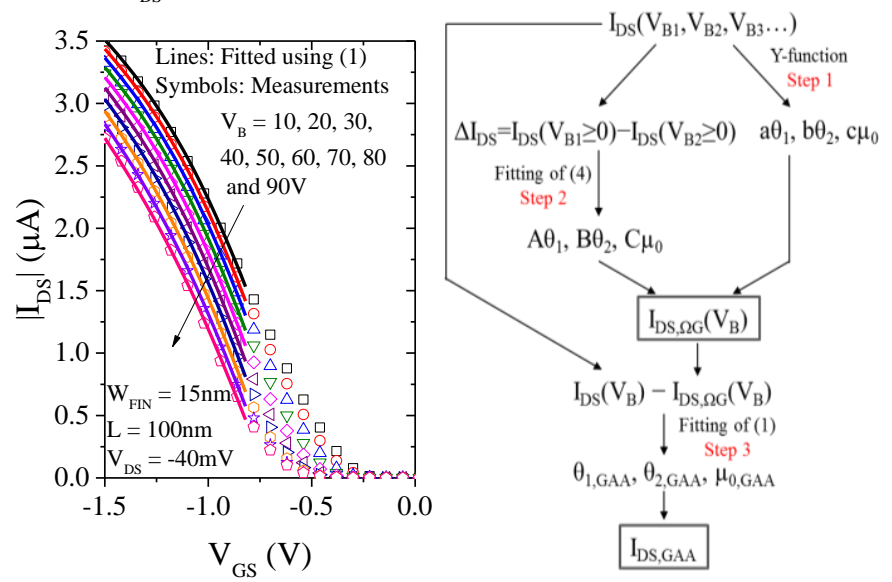

Fig. 5. (a) Step 3. Measurements and model results of $I_{D S} v s$. $V_{G S}$ for $N W$ with $\mathrm{W}_{\mathrm{FIN}}=15 \mathrm{~nm}, \mathrm{~L}=100 \mathrm{~nm}$ and $\mathrm{V}_{\mathrm{DS}}=-40 \mathrm{mV}$. (b) Schematic representation of the proposed method highlighting steps 1 to 3 . 
Step 3.- Once all parameters for the $\Omega$-NW are determined, $\mathrm{I}_{\mathrm{DS}, \Omega \mathrm{G}}$ can be calculated and, by fitting $\mathrm{I}_{\mathrm{DS}}$ measurements to (1), it is possible to extract $\mu_{0, \mathrm{GAA}}, \theta_{1, \mathrm{GAA}}$ and $\theta_{2, \mathrm{GAA}}$. This last step of the proposed methodology is presented in Fig. 5-a.

The schematics of the entire procedure is shown in Fig. 5-b. Fig. 6 indicates the obtained parameters for both $\Omega$ - and GAANWs of the stacked structure. Similar $\mu_{0}$ and $\left(1+\theta_{1} \mathrm{~V}_{\mathrm{GT}}+\right.$ $\theta_{2} V_{\mathrm{GT}^{2}}$ ) behavior with $\mathrm{V}_{\mathrm{B}}$ is found by comparing the stacked $\Omega$-NW and the non-stacked TG NW corroborating with the validity of the proposed method.

The proposed method has been applied in stacked NWs, varying $\mathrm{T}$ from $25^{\circ} \mathrm{C}$ up to $150^{\circ} \mathrm{C}$. The $\mu_{0, \Omega \mathrm{G}}$ increases with $\mathrm{V}_{\mathrm{B}}$ decrease, evidenced in Figs. 6 and 7, is in agreement with previous reported work in literature [7]. It is mainly explained by the inversion charge distribution in the NW channel modulated by $\mathrm{V}_{\mathrm{B}}$, and the position from $\mathrm{Si} /$ insulator interface. At $\mathrm{V}_{\mathrm{B}}=0 \mathrm{~V}$, Fig.7-b shows that both $\Omega$ - and GAA-NWs present similar $\mu_{0}$ slope varying $\mathrm{T},-0.12$ and $-0.11 \mathrm{~cm}^{2} / \mathrm{V}$.s. ${ }^{\circ} \mathrm{C}$,
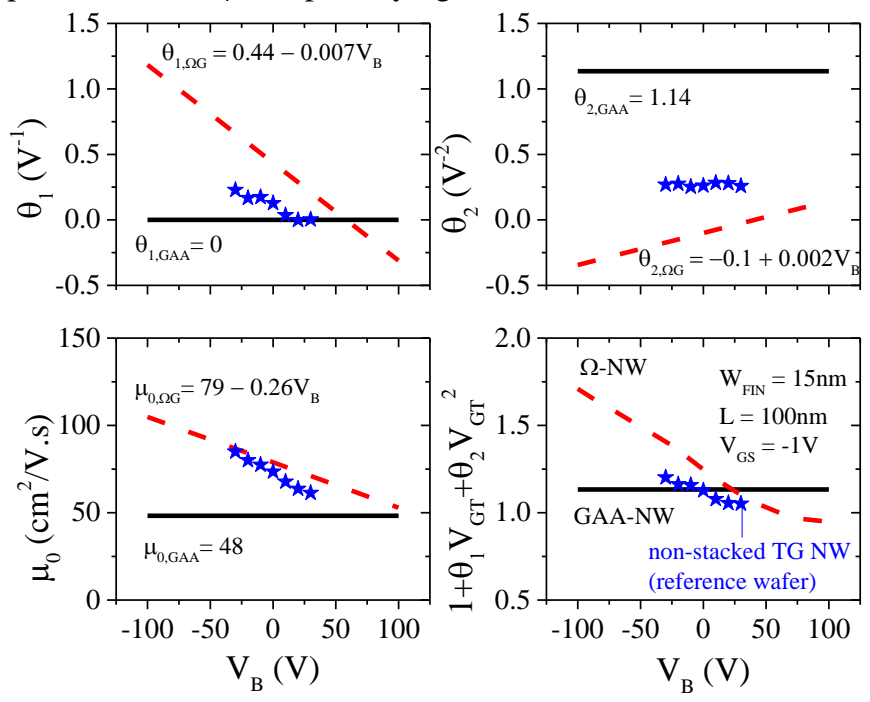

Fig. 6. Extracted parameters through the proposed methodology for NWs with $\mathrm{W}_{\mathrm{FIN}}=15 \mathrm{~nm}$ and $\mathrm{L}=100 \mathrm{~nm}$.
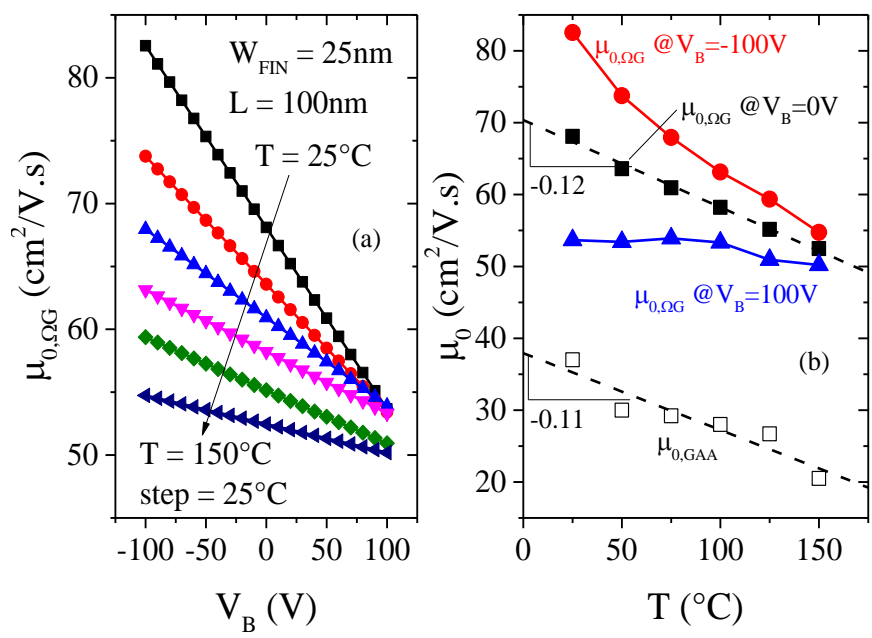

Fig. 7. $\mu_{0, \Omega \mathrm{G}}$ vs. $V_{\mathrm{B}}$, varying $\mathrm{T}$ (a) and $\mu_{0}$ for both top GAA and bottom $\Omega$ NWs vs. $T$ (b), varying $\mathrm{V}_{B}$ for NW with $\mathrm{W}_{\mathrm{FIN}}=25 \mathrm{~nm}$ and $\mathrm{L}=100 \mathrm{~nm}$. respectively. The linear mobility decrease with $\mathrm{T}$ increase is dominated by phonon scattering. However, Fig. 7 shows a strong increase of $\mu_{0}$ T-dependence by decreasing $V_{B}$, in agreement with reduced surface roughness contribution and higher phonon scattering contribution at negative $\mathrm{V}_{\mathrm{B}}$.

\section{CONCLUSIONS}

The improved method for separating the contributions of each NW on stacked NW SOI MOSFETs by means of back bias variation has shown to be a powerful tool for electrical parameters extraction. The proposed method allows for accurate description of the measured trends in a wide range of $\mathrm{V}_{\mathrm{B}}$ and temperature. The linear behavior between mobility parameters and $\mathrm{V}_{\mathrm{B}}$, which has also been evidenced in nonstacked TG NWs, must be taken into account in order to correctly describe the drain current of narrow NW SOI MOSFETs. Lower mobility values extracted to GAA-NWs are in agreement with results in literature, due to lower hole mobility of (100)/[110] surface conduction and stronger surface roughness degradation. The proposed method also revealed that the mobility dependence on $\mathrm{T}$ for $\Omega-\mathrm{NW}$ remarkably vary with $V_{B}$ in the studied range.

\section{ACKNOWLEDGMENT}

This work was partially carried out thanks to the French Public Authorities from NANO 2017 program, CNPq and São Paulo Research Foundation (FAPESP) grants 2015/10491-7 and 2016/06301-0.

This work is also partially funded by the SUPERAID7 (grant $\mathrm{N}^{\circ} 688101$ ) project.

\section{REFERENCES}

[1] S. Barraud et al., "Performance of Omega-Shaped-Gate Silicon Nanowire MOSFET With Diameter Down to $8 \mathrm{~nm}$," IEEE Electron Device Letters, vol. 33, no. 11, pp. 1526-1528, Nov. 2012.

[2] C. Dupré et al., "15nm-diameter 3D stacked nanowires with independent gates operation: $\Phi F E T$," in IEEE International Electron Devices Meeting, 2008.

[3] S. Barraud et al., "Vertically stacked-NanoWires MOSFETs in a replacement metal gate process with inner spacer and $\mathrm{SiGe}$ source/drain," in IEEE International Electron Devices Meeting, 2016.

[4] H. Mertens et al., "Vertically stacked gate-all-around Si nanowire CMOS transistors with dual work function metal gates," in IEEE International Electron Devices Meeting, 2016.

[5] B. C. Paz et al., "Performance and Transport Analysis of Vertically Stacked p-FET SOI Nanowires," in Joint International EUROSOI Workshop and International Conference on Ultimate Integration on Silicon (EUROSOI-ULIS), 2017, pp. 79-82.

[6] C. Dupré et al., "Method for 3D electrical parameters dissociation and extraction in multichannel MOSFET (MCFET)," Solid-State Electronics, vol. 53, no. 7, pp. 746-752, Jul. 2009.

[7] E. G. Marin, F. G. Ruiz, A. Godoy, I. M. Tienda-Luna, C. MartinezBlanque, and F. Gámiz, "Impact of the Back-Gate Biasing on Trigate MOSFET Electron Mobility," IEEE Transactions on Electron Devices, vol. 62, no. 1, pp. 224-227, Jan. 2015.

[8] S. Cristoloveanu, S. Athanasiou, M. Bawedin, and P. Galy, "Evidence of Supercoupling Effect in Ultrathin Silicon Layers Using a Four-Gate MOSFET," IEEE Electron Device Letters, vol. 38, no. 2, pp. 157-159, Feb. 2017.

[9] G. Ghibaudo, "New method for the extraction of MOSFET parameters," Electronics Letters, vol. 24, no. 9, pp. 543-545, Apr. 1988. 